\title{
Monitoramento de Custos e do Passivo Socioambiental: Uma Proposta de Arquitetura de Dados de Sustentabilidade
}

\author{
Takeshy Tachizawa \\ Pós-Doutorado em Business and Management - University of California \\ Professor da Faculdade Campo Limpo Paulista - FACCAMP \\ Rua Guatemala, 167. Jardim América (IECLP). Campo Limpo Paulista/SP. CEP: \\ $13231-230$ \\ E-mail: usptakes@uol.com.br
}

\section{RESUMO}

O artigo apresenta uma arquitetura de dados de custos socioambientais para diagnóstico das organizações em termos de sustentabilidade econômica. É proposto um modelo de base de dados de indicadores de diferenciação de custos socioambientais, fundamentado em pesquisa empírica, desenvolvida pelo método grounded theory. A ênfase da grounded theory é o aprendizado a partir dos dados (interativa e indutiva), e não a partir de uma visão teórica existente (dedutiva). Tais indicadores, além de refletir o estágio de sustentabilidade em que se encontra a empresa analisada, subsidiariam 0 mapeamento socioambiental dos diferentes segmentos econômicos do universo empresarial brasileiro. A arquitetura, estruturada com o suporte de recursos das tecnologias da informação possibilitaria o planejamento de decisões inerentes à gestão de custos socioambientais de sua cadeia produtiva.

Palavras-chave: Custos socioambientais. Arquitetura de dados de sustentabilidade. Diagnóstico das organizações.

\section{Monitoring of Accountability Costs: A Porposal for Architecture of Data Sustentability}

\section{ABSTRACT}

This article presents an architecture of data for diagnosis of social costs of organizations in terms of economic sustainability. It proposed a model of the database of indicators of social differentiation of costs, based on empirical research, developed based on the method grounded theory. The emphasis of grounded theory is to learn from the data (interactive and inductive), and not from a theoretical vision existing (deductive). Such indicators reflect the stage of sustainability where the company tested and sinalyzing the mapping of different socio economic segments of the Brazilian business universe. The architecture, structured with the support of information technology resources would allow the planning decisions inherent in the management of social costs of their production chain. 
Key Words: Accountability costs. Architecture of data sustainability. Organizations diagnostic.

\section{INTRODUÇÃO}

A responsabilidade socioambiental corporativa, na trilha de desastres socioambientais envolvendo organizações globalizadas, ganha importância como instrumento de gestão da controladoria para evitar riscos econômicos. Os clientes, neste novo cenário empresarial, têm expectativas de interagir com organizações que sejam éticas, tenham boa imagem institucional no mercado, e que atuem de forma ecologicamente responsável. Neste ambiente, emerge a questão da sustentabilidade, que enfatiza o compromisso dos gestores junto aos stakeholders, como instrumento de gestão para a otimização econômica da organização.

Neste contexto, foram analisados os fatores de influência da sustentabilidade nas empresas brasileiras e as possibilidades do uso de indicadores de diferenciação de custos socioambientais, proposta do presente trabalho. Foram abordadas as atividades econômicas exercidas pelas organizações, em seus diferentes ramos de negócios, relacionando-as com suas características de sustentabilidade.

Como decorrência desta análise, estabeleceu-se uma metodologia para o diagnóstico socioambiental com enfoque diferenciado para cada tipo de organização do cenário empresarial brasileiro. Este diagnóstico permitiu estruturar um indicador de desenvolvimento socioambiental - IDS que levasse em conta as peculiaridades existentes nas empresas em função do seu setor econômico de atuação. Com isso ele pode se constituir em uma referência para análise dos custos socioambientais, que seriam singulares aos efeitos da sustentabilidade, intrínsecos a cada setor econômico.

O princípio que serviu de base para a composição do IDS, está fundamentado na avaliação do desenvolvimento na empresa, não do ponto de vista do crescimento econômico, mas pelo prisma de outras dimensões capazes, de interpretar a sustentabilidade de suas ações empresariais. Estas dimensões, em sintonia com o potencial crescimento profissional dos colaboradores da empresa, na medida em que convivem com saudáveis práticas de qualidade de vida, constituiu o embasamento 
filosófico deste trabalho, quais sejam: cidadania corporativa; transparência; governança corporativa; e capital humano. O IDS, portanto, objetivou o desenvolvimento de uma métrica que espelhasse o estágio evolutivo da organização em termos socioambientais, em seu contexto interno e externo.

As razões que justificariam seu uso como instrumento de gestão pelas empresas não são apenas decorrentes de aderência à legislação vigente, mas, principalmente, em função da possibilidade de direcionar as decisões de gestão de custos e da controladoria de forma convergente com os objetivos da sustentabilidade empresarial.

\section{FUNDAMENTAÇÃO TEÓRICA}

Problemas como poluição, falta de segurança, corrupção, má gestão dos recursos públicos, falta de ética, e tantos outros, perpassam toda a história da humanidade desde o surgimento dos primeiros agrupamentos urbanos, ainda na Antiguidade (TACHIZAWA, 2009). Para Henderson (2001), tal perspectiva tem se acentuado no mundo contemporâneo, como decorrência das mutações ocorridas na escala de valores e crenças do ser humano, delineadas pela Revolução Industrial. Essas mutações evoluíram para os tempos atuais como responsabilidade social. Esta é entendida como a forma de gestão que se define pela relação ética e transparente da empresa com os públicos com os quais ela se relaciona e pelo estabelecimento de metas empresariais compatíveis com o desenvolvimento sustentável, preservando recursos ambientais e culturais para as gerações futuras (INSTITUTO ETHOS, 2008).

O envolvimento empresarial em ações sociais na comunidade começou na forma de ações voluntárias das empresas, focando problemas sociais (BRONN; VRIONI, 2001). Uma das principais características presentes nesse cenário é a mudança no conceito do que é importante, do que tem valor, das metas a serem atingidas e dos meios de medição (indicadores) do progresso coletivo para alcançar tais metas (HENDERSON, 2001). Estes instrumentos de mensuração irão desempenhar diferentes papéis sob vários aspectos, pois orientam o campo econômico e social, sendo indispensáveis aos pesquisadores e empresários, além de contribuir para que o 
Monitoramento de Custos e do Passivo Socioambiental: Uma Proposta de Arquitetura de Dados de Sustentabilidade

Takeshy Tachizawa

cidadão possa ter diferentes visões do que está ocorrendo na sociedade (BESSERMAN, 2003).

Para a Organization for Economic Co-operation and Development - OECD (2008), um indicador deve ser entendido como um parâmetro, ou valor derivado de parâmetro, que aponta e fornece informações sobre o estado de um fenômeno com uma extensão significativa. Evans e Würster (2000) prescreveram a importância estratégica da informação que deixou de ser apenas uma ferramenta de controle para os gestores e tomou posição de um recurso básico que justifica sua utilização como base para a formulação de indicadores, principalmente para suporte ao processo decisório (LAUDON; LAUDON, 2000; RAYPORT; JAWORSKI, 2001).

O Programa das Nações Unidas para o Desenvolvimento (PNUD, 2008) publicou o Índice de Desenvolvimento Humano (IDH) com propósito de desafiar as estreitas definições econômicas de progresso que compõem o Produto Interno Bruto (PIB). O IDH incorpora, além dos indicadores econômicos, os sociais, as estatísticas sobre os índices de alfabetização, a média da expectativa de vida e o poder de compra. $\mathrm{O}$ IDH tornou-se, pois, o mais importante instrumento de medida e de comparação da condição de vida não só de países, mas também de espaços menores como estados e municípios (BESSERMAN, 2003). A Comissão de Desenvolvimento Sustentável da ONU publicou, em 1996, o documento 'Indicadores de Desenvolvimento Sustentável estrutura e metodologia', apresentando um conjunto de indicadores econômicos, sociais e ambientais (IBGE, 2008).

Neste cenário se insere a ISO14000, para meio ambiente e, mais recentemente, a ISO16000, AA1000 e SA8000 (TINOCO, 2001), como certificações sociais com o objetivo de atestar que a organização, além de ter procedimentos internos corretos, participa de ações não lucrativas. A Organização para a Cooperação e o Desenvolvimento Econômico - OCDE recomenda que as organizações, públicas e privadas, adotem princípios focados na transparência de suas ações. O balanço social se insere neste cenário de transparência e disseminação de informações junto aos seus diferentes públicos (RAYNARD; FORSTARTER, 2002). 
O Instituto Ethos de Responsabilidade Social (ETHOS, 2008) sugere um padrão de balanço social, que explicita os impactos da atividade da empresa na sociedade e evidencia o relacionamento com os seus diferentes públicos. O modelo Ethos considera, ainda, a apresentação do relatório sugerido pelo Instituto Brasileiro de Análises Sociais e Econômicas (IBASE, 2008), e constitui uma alternativa de evidenciação das atividades empresariais através de balanço social.

A Bolsa de Valores de São Paulo (BOVESPA, 2008), face ao crescente interesse dos investidores em migrar para os portfólios verdes, e em resposta à demanda de bancos, fundos de pensão e gestores de recursos, organizou um índice de responsabilidade social e sustentabilidade (índice de sustentabilidade empresarial ISE), baseado no Dow Jones Sustainability Indexes da Bolsa de Nova York - DJSI. Este indicador global de sustentabilidade monitora o desempenho financeiro das companhias de capital aberto. O DJ-SI, segundo Tachizawa e Andrade (2008), pondera em sua composição, a importância da integração dos fatores econômicos, ambientais e sociais na estratégia da empresa e avalia aspectos como inovação tecnológica, governança corporativa, interesse dos investidores, expectativas dos públicos de interesse, liderança e capacidade de resposta às mudanças sociais.

Nesse sentido, torna-se fundamental aprimorar o processo de armazenamento e recuperação de informações, razão pela qual Draper e Dunlop (2008) procuraram desenvolver métodos de identificar e acessar informações relevantes segundo a percepção dos usuários de nível estratégico nas empresas. Fica evidente a necessidade de estudos para uma consideração mais abrangente dos requisitos do processo de busca de informações empresariais relevantes, nos contornos do conceito de inteligência dos negócios. O entendimento das necessidades de informação de uma organização neste cenário é um tema dominante nas discussões. Vindo ao encontro disso, emerge o conceito de gerenciamento de desempenho corporativo (corporate performance management - CPM), cuja questão-chave não é só medir, mas projetar um processo que contemple decidir quais necessidades podem ser medidas, como e quando (BUYTENDIJK; WOOD; GEISHECKER, 2004). 
Monitoramento de Custos e do Passivo Socioambiental: Uma Proposta de Arquitetura de Dados de Sustentabilidade

Takeshy Tachizawa

Motivado pela existência de uma lacuna entre o que os gestores necessitam em termos de sustentabilidade e o que ocorre no dia-a-dia das operações empresariais, foi desenvolvido o presente trabalho.

\section{METODOLOGIA DA PESQUISA}

Os dados da pesquisa empírica, desenvolvida ao longo do primeiro semestre de 2008, e obtidos segundo uma perspectiva indutiva, foram base do presente estudo. Nesta pesquisa, foi utilizado o método grounded theory (GLASER; STRAUSS, 1967) que é uma modalidade de pesquisa que busca gerar novas teorias através de conceitos, categorias e propriedades. A ênfase da grounded theory é o aprendizado a partir dos dados (interativa e indutiva), e não a partir de uma visão teórica existente (dedutiva). A maior diferença entre grounded theory e outros métodos de pesquisa é seu foco específico no desenvolvimento da teoria, através de uma contínua interdependência entre a coleta e a análise de dados.

É um método que provê uma estrutura metodológica freqüentemente ausente em outras abordagens, tanto qualitativa como quantitativa, sem sacrificar a flexibilidade ou o rigor. A grounded theory foi desenvolvida no âmbito da pesquisa em ciências sociais, enfatizando a descoberta indutiva de teorias a partir dos dados analisados sistematicamente. Outros autores desenvolveram e debateram o método (GLASER, 1998; GLASER; HOLTON, 2004; STRAUSS; CORBIN, 1994; STRAUSS; CORBIN, 1997) reafirmando que: (a) a proposta principal do método é a construção de teoria, e não somente a codificação e análise de dados; (b) regra geral, o pesquisador não deve definir um quadro conceitual que antecede ao início da pesquisa, como premissa, para garantir que os conceitos possam emergir sem vieses conceituais pré-definidos; (c) a análise e a conceituação são obtidas através do processo de coleta de dados e comparação constante, no qual cada segmento de dados é comparado com construtos existentes, visando enriquecer uma categoria existente, formar uma nova ou estabelecer novos pontos de relação entre categorias.

O universo desta pesquisa foi o conjunto das maiores organizações do ramo industrial, comercial e de prestação de serviços que atuam na economia nacional 
(REVISTA EXAME, 2008). A coleta de dados foi efetuada mediante a utilização de questionários eletrônicos, encaminhados diretamente aos executivos das 1.000 maiores empresas brasileiras, conforme critério da publicação Melhores e Maiores (REVISTA EXAME, 2008) e das 150 melhores empresas em cidadania corporativa (REVISTA EXAME, 2008).

Complementando as respostas dos questionários preenchidos, foram obtidas informações disponibilizadas diretamente nos sites corporativos das mesmas empresas da amostra pesquisada. Foram consideradas respostas de 458 empresas, do total das organizações pesquisadas. Balanços sociais e relatórios de sustentabilidade foram acessados, via Internet, junto às empresas da amostra, para fins de análise adicional. Foram consideradas, também, informações específicas obtidas de sites do Instituto Ethos, Ibase, Bovespa, IBGC, Revista Exame, Época e publicações especializadas em negócios.

\section{ANÁLISE DOS RESULTADOS}

Para a concepção da arquitetura de dados socioambientais, procurou-se analisar as respostas das 458 empresas que responderam a pesquisa (42\% de respostas em relação ao total das 1.150 empresas pré-selecionadas), o que permitiu estabelecer uma compreensão da sustentabilidade das organizações da economia nacional.

Pela aplicação do questionário eletrônico e acesso aos sites das empresas ao longo do ano de 2008, obtiveram-se dados relativos aos setores de atuação, constatando-se uma predominância das empresas industriais. Pelos dados primários coletados, ficou evidenciado que $65,7 \%$ do total das empresas da amostra que responderam ao questionário são indústrias, seguido das empresas de serviços com $21,6 \%$ e, complementarmente, $12,7 \%$ de empresas comerciais.

Para entender metodologicamente a proposta de classificação das organizações em termos de sustentabilidade, considerou-se, inicialmente, uma classificação simples (organizações industriais, comerciais e de serviços), para posteriormente adotar uma 
tipologia mais completa de organizações que são interligadas entre si no ambiente empresarial brasileiro.

Como empresas do setor industrial, enquadraram-se as organizações relacionadas a atividades vinculadas à siderurgia, ao cimento, ao papel e celulose, ao segmento metal-mecânico, à metalurgia, ao segmento automotivo, e a assemelhadas (bens duráveis e de consumo). São aquelas empresas que transformam insumos produtivos (matérias primas em geral) em produtos acabados.

Já as empresas prestadoras de serviços foram enquadradas como tal, aquelas prestadoras de serviços financeiros (bancos, financeiras e corretoras valores e seguros), engenharia, publicidade e propaganda, hospitais, hotelaria e afins. Como empresas comerciais foram consideradas aquelas dedicadas ao ramo atacadista e varejista (lojas comerciais, distribuidoras e correlatas).

Outra indagação inserida na pesquisa foi em relação ao foco de atuação da empresa em termos de sustentabilidade, cuja incidência de respostas é evidenciada na Tabela 01.

Tabela 1- Ações socioambientais aferidas na pesquisa

\begin{tabular}{|c|r|r|r|}
\hline DISCRIMINACÃO & SERVIÇOS & INDUSTRIAL & COMERCIAL \\
\hline Educação & $36,4 \%$ & $44,7 \%$ & $29,5 \%$ \\
\hline Meio ambiente & $11,9 \%$ & $75,8 \%$ & $43,1 \%$ \\
\hline Saúde & $37,8 \%$ & $22,3 \%$ & $35,4 \%$ \\
\hline $\begin{array}{c}\text { Ações } \\
\text { Comunitárias }\end{array}$ & $44,3 \%$ & $31,1 \%$ & $49,8 \%$ \\
\hline
\end{tabular}

Pelas respostas, evidenciou-se uma preponderância de ações de proteção ambiental nas empresas industriais (75,8\%). Nas demais empresas, serviços $(11,9 \%)$ e comerciais $(43,1 \%)$, notou-se menor ênfase com relação ao meio ambiente. Outras ações sociais e comunitárias (voluntariado, cultura, segurança, inclusão social, portadores de necessidades especiais, criança e adolescente, pessoas da terceira idade e proteção de animais) distribuíram-se, com ligeiro destaque aos setores comerciais e de serviços. 
As características socioambientais aferidas na pesquisa evidenciaram impactos de sustentabilidade diferenciados para cada tipo de empresa (Quadro 1). Os resultados da análise destes fatores de influência pesquisados permitiram a identificação de características socioambientais intrínsecas a cada tipo de organização.

\begin{tabular}{|c|r|r|r|}
\hline $\begin{array}{c}\text { FATORES } \\
\text { PESQUISADOS }\end{array}$ & SERVIÇOS & INDÚSTRIA & COMÉRCIO \\
\hline $\begin{array}{c}\text { a) cadeia } \\
\text { produtiva sustentável }\end{array}$ & Baixo & Alto & Médio \\
\hline $\begin{array}{c}\text { b) impacto da } \\
\text { produção no meio } \\
\text { ambiente }\end{array}$ & Nulo & Alto & Baixo \\
\hline $\begin{array}{c}\text { c) impacto do } \\
\text { produto no meio } \\
\text { ambiente }\end{array}$ & Nulo & Alto & Baixo \\
\hline $\begin{array}{c}\text { d) fornecedores } \\
\text { observam requisitos } \\
\text { socioambientais }\end{array}$ & Baixo & Alto & Médio \\
\hline $\begin{array}{c}\text { e) barreiras } \\
\text { institucionais/legais }\end{array}$ & Baixo & Alto & Médio \\
\hline $\begin{array}{c}\text { f) exigência } \\
\text { recursos financeiros }\end{array}$ & Baixo & Alto & Médio \\
\hline
\end{tabular}

Quadro 1: Características socioambientais aferidas na pesquisa

Tais tipos de organizações do universo empresarial brasileiro são, inicialmente, classificados de forma simples, de acordo com a afinidade dos fatores pesquisados. Esses fatores (passivo socioambiental), posteriormente, foram ampliados, viabilizando dessa maneira, atingir o agrupamento de 10 tipos de organizações (Figura 2), conforme proposto neste trabalho.

$\mathrm{Na}$ Figura 1, ilustrada a seguir, pode-se verificar os efeitos socioambientais diferenciados nas empresas dos três setores da economia. 


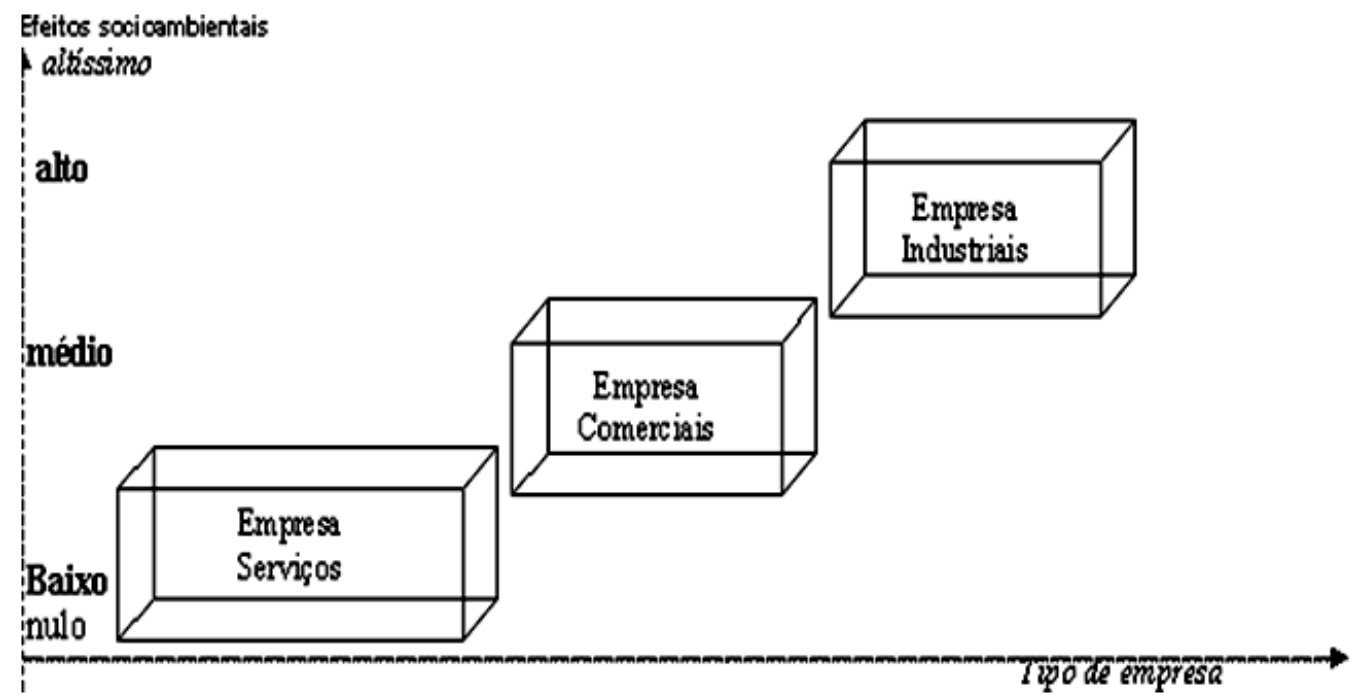

Figura 1: Efeitos socioambientais e os setores econômicos

De acordo com a Figura 1, nota-se que a linha horizontal representa o tipo de empresa e na linha vertical o grau de efeito socioambiental, potencialmente causado pela empresa.

Analisando os diferentes tipos de organizações, tem-se que as empresas prestadoras de serviços apresentam efeitos socioambientais quase nulos, resumindo suas estratégias socioambientais às práticas de marketing institucional em termos de divulgação de balanços sociais e projetos sociais implementados nas áreas de: educação; cultura; voluntariado; e ações correlatas.

No outro extremo, têm-se as empresas industriais causadoras, em potencial, de maiores impactos socioambientais, tais como aquelas vinculadas à siderurgia, cimento, papel e celulose, energia e similares.

Fazendo uma análise, agora detalhada, dos fatores socioambientais pesquisados nas empresas da amostra (Quadro 1), puderam ser identificadas características de sustentabilidade diferenciadas, em função do tipo de organização, conforme pode ser observado na ilustração da Figura 2.

Nesta Figura 2, são apresentadas as características e grau de atuação socioambiental percebidos nos setores econômicos com relação aos fatores pesquisados. Tem-se um eixo de coordenadas onde a linha horizontal representa o tipo 
de empresa e na coluna tem-se o grau de impacto na comunidade e, portanto, exigências diferenciadas em termos de responsabilidade socioambiental, normalmente, praticadas pela empresa.
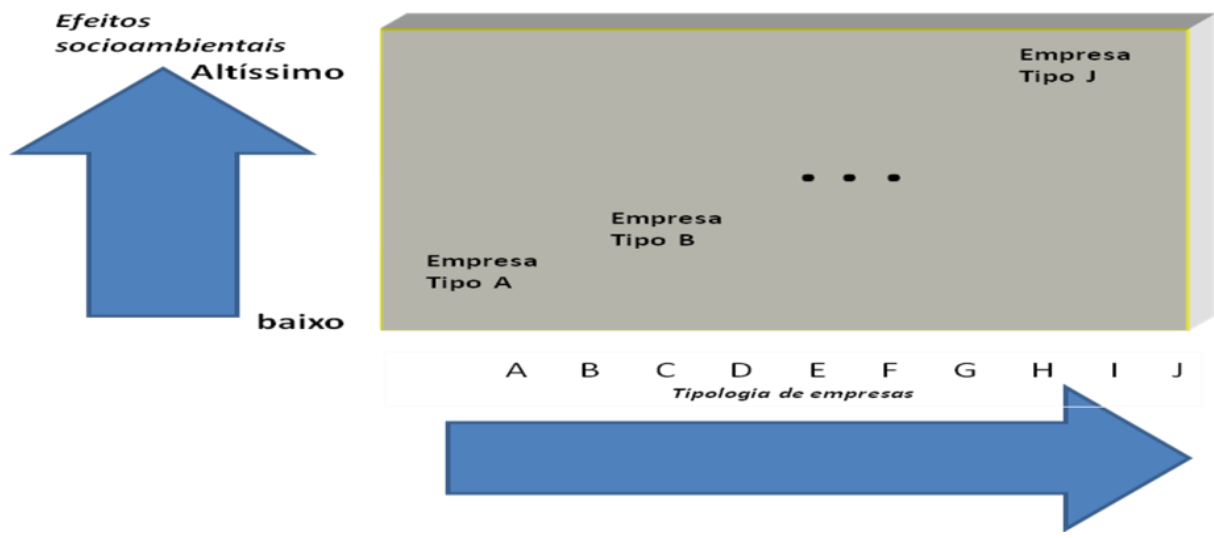

Figura 2: Diferenciação das organizações em face de suas características socioambientais

Analisando os diferentes tipos de empresas, conforme modelo proposto, deduzse que os bancos apresentam impactos ambientais quase nulos, resumindo suas estratégias ambientais e sociais, praticamente, à divulgação de balanços sociais e projetos sociais comunitários. Ao lado dos bancos têm-se outras organizações como as instituições de ensino, empresas de serviços especializados que, além de enfatizarem essencialmente as estratégias sociais adotam, ainda, estratégias de tecnologias da informação que demandam efeitos favoráveis ao processo de gestão socioambiental, mesmo nestas organizações de baixíssimo impacto ambiental. No outro extremo, têmse as empresas da indústria altamente concentrada, provocadoras de fortíssimos impactos ambientais, tais como: siderúrgicas, cimento, papel e celulose, hidrelétricas e afins.

Entre estes dois extremos têm-se os outros tipos de empresas (empresas comerciais, empresas produtoras de bens de consumo duráveis, e outros tipos) que, normalmente, podem adotar estratégias socioambientais compatíveis com o grau de impactos ambientais causados pelos seus processos e estratégias sociais coerentes em função do grau de expectativa da comunidade na qual está inserida. 
Os efeitos socioambientais nas empresas puderam ser graduados em 10 tipos de acordo com suas atividades econômicas e, portanto, em função do setor econômico a que pertencem. Desde empresas de baixo impacto socioambiental, como decorrência natural de suas atividades econômicas, que assumem comportamento ético também compatível com esta ínfima exigência em termos de responsabilidade social, até empresas do setor altamente concentrado, que adotam processo de avaliação de impactos dos produtos, processos e instalações, que precisa ser sistematizado, buscando antecipar às demandas e questões públicas. Esta última categoria de empresas, normalmente, necessita de certificação internacional do tipo selo verde e/ou equivalentes instituídos pela SA8000, AA1000, ISO14000 e congêneres.

Os 10 tipos de organizações, classificadas segundo seus efeitos socioambientais (Passivo) pertinentes, são propostos e descritos a seguir:

Organizações sociais (tipo A): a organização assume responsabilidades perante a sociedade e toma ações em relação ao exercício da cidadania coerente às suas atividades econômicas. A promoção do comportamento ético também é compatível com seu ramo de negócios de baixo impacto ambiental e ínfima exigência em termos de responsabilidade social. É o caso de cooperativas e associações; organizações sociais; e atividades correlatas.

Empresas de serviços (tipo B): A organização reconhece os impactos causados por seus produtos, processos e instalações, apresentando algumas ações isoladas no sentido de minimizá-los. Enfatiza a promoção do comportamento ético. Posicionamento, normalmente, exigido para empresas de prestação de serviços especializados; firmas de engenharia; e organizações afins.

Empresas comerciais (tipo $\mathrm{C}$ ): A organização adota práticas socioambientais para atenuar os potenciais impactos dos produtos comercializados, processos e instalações. Tende a exercer certa liderança em questões de interesse da comunidade. Existe envolvimento das pessoas em esforços de desenvolvimento social. Médias e grandes organizações do setor de comércio varejista e atacadista; e afins.

Instituições financeiras (tipo D): A organização adota práticas socioambientais para atenuar os impactos de seus serviços, processos e instalações. Promove o 
comportamento ético. Empresas prestadoras de serviços financeiros; bancos; seguradoras; e empresas de serviços em geral.

Hospitais e Hotelaria (tipo E): A organização adota práticas socioambientais para atenuar os impactos de seus serviços, processos e instalações. Lidera questões de interesse da comunidade e do setor. O estímulo à participação das pessoas em esforços de desenvolvimento social é sistemático. Existem formas implementadas de avaliação e melhoria da atuação da organização no exercício da cidadania e no tratamento de suas responsabilidades públicas. Posicionamento, normalmente, exigido para hotéis, hospitais e organizações prestadoras de serviços de lazer e entretenimento.

Empresas de médio efeito socioambiental (tipo F): A organização adota práticas socioambientais para atenuar os médios impactos de seus produtos, processos e instalações. Busca antecipar as questões públicas. A empresa publica balanços sociais e cumpre padrões anteriormente estruturados nos estágios anteriores. Posicionamento, normalmente, exigido para empresas de materiais de construção; do setor automotivo; confecções e têxteis; e higiene e cosméticos.

Indústria de bens de consumo não-duráveis (tipo G): O processo de avaliação dos impactos dos produtos, processos e instalações precisa ser sistematizado, buscando antecipar as questões públicas. A empresa necessita, normalmente, de certificação internacional do tipo selo verde e/ou equivalentes instituídos pela SA8000, AA1000 e equivalentes. É o caso das empresas pertencentes a setores econômicos como: alimentos; agronegócios; e atividades correlatas de alto impacto socioambiental.

Indústria de bens de consumo duráveis (tipo $\mathrm{H}$ ): $\mathrm{O}$ processo de avaliação dos impactos dos produtos, processos e instalações precisa ser sistematizado, buscando antecipar as questões públicas. Adota, normalmente, certificação internacional do tipo selo verde e/ou equivalentes instituídos pela SA8000, AA1000 e equivalentes. É o caso das empresas pertencentes a setores econômicos como: construção pesada; plásticos e borracha; eletroeletrônicos; metalurgia e atividades correlatas de significativo impacto socioambiental. 
Indústrias de alto efeito socioambiental (tipo I): O processo de avaliação dos impactos dos produtos, processos e instalações precisa ser sistematizado, buscando antecipar as questões públicas. A empresa necessita de certificação internacional do tipo selo verde e/ou equivalentes instituídos pela SA8000, AA1000 e equivalentes. Deve adotar princípios de governança corporativa e cumpre padrões cumulativamente estruturados nos tipos anteriores. Neste nível alcançado pelas organizações deste tipo, deve ser considerada como uma exigência a ser "cobrada" das grandes organizações, cujas características socioambientais exigem tal posicionamento. É o caso das empresas pertencentes a setores econômicos como: papel e celulose; tabaco; farmacêutico; bebidas; química leve; e atividades correlatas de alto impacto socioambiental. São empresas de capital altamente concentrado e aplica-se àquelas de grande porte com ações em bolsa de valores.

Indústrias de altíssimo efeito socioambiental (tipo J): O processo de avaliação dos impactos dos produtos, processos e instalações precisa ser sistematizado, buscando antecipar as questões públicas. A empresa necessita de certificação internacional do tipo selo verde e/ou equivalentes instituídos pela SA8000, AA1000 e congêneres. Deve adotar princípios de governança corporativa e cumpre padrões cumulativamente estruturados nos tipos de organização anteriormente descritos. É o caso das empresas pertencentes a setores econômicos como: petroquímica; química pesada; mineração; hidrelétricas; termoelétricas e usinas nucleares; cimento; fabricantes de munições; armamento militar; fabricantes de agrotóxicos; produtoras de sementes transgênicas e atividades correlatas de altíssimo impacto socioambiental. São empresas de capital altamente concentrado e aplica-se àquelas de grande porte com ações em bolsa.

A caracterização de cada tipo pode ser útil para sinalizar suas respectivas ações gerenciais correspondentes na forma de estratégias de sustentabilidade econômica. Esta tipologia permitiria, ainda, estruturar uma base de dados de forma a agrupar, em um mesmo lócus virtual, informações de referência acerca da sustentabilidade empresarial e, principalmente, de dados de custos socioambientais. 


\section{BASE DE DADOS DE INDICADORES DE CUSTOS SOCIOAMBIENTAIS}

\subsection{Mapeamento socioambiental}

Ficou evidente, pelos resultados da pesquisa, que uma empresa, qualquer que seja seu estilo de gestão, possui "efeitos" socioambientais, que são diferenciados em decorrência natural do setor econômico no qual está inserida. Estes efeitos, de acordo com o diagnóstico de sustentabilidade proposto neste trabalho (Quadro 2), podem ser representados na forma de passivo socioambiental. Para fazer frente a estes efeitos, a empresa necessita implementar ações correspondentes como contrapartida, na forma de deveres e obrigações (ativo socioambiental).

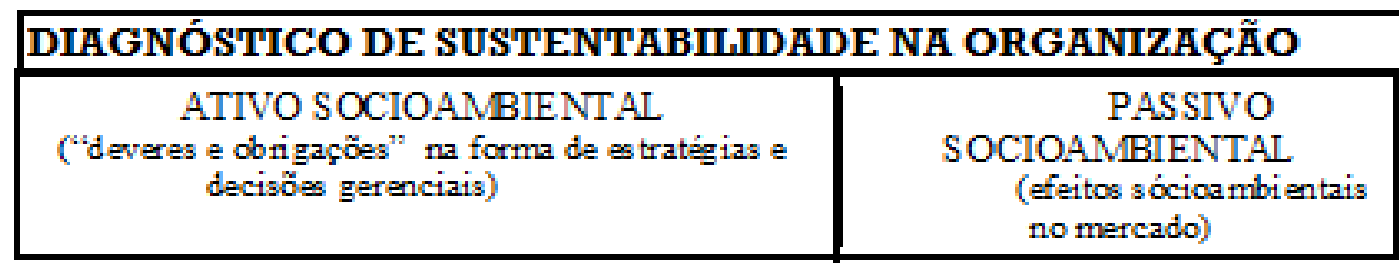

Quadro 2: Ativo e Passivo Socioambiental

O ativo (custos socioambientais) corresponderia ao quanto de ações socioambientais seria necessário adotar, por iniciativa da direção da empresa, para preservar os processos produtivos de forma sustentável. É o quanto de insumos produtivos e de providências gerenciais é necessário para continuar a produzir bens e serviços que consomem e absorvem recursos produtivos na forma de matérias-primas.

A analogia, simplificada, que se pode fazer é com uma pessoa de classe média, que possui carro para trabalhar. Esta pessoa, com seu carro, consome gasolina que emite gás carbônico, equivalente a uma árvore que teria que plantar, mensalmente, para compensar tal efeito ambiental nocivo. Neste raciocínio simplista, como há uma equivalência entre os efeitos socioambientais provocados pelo consumo mensal de gasolina (custos socioambientais pela metodologia ora proposta) com a "compensação" na forma da árvore plantada, o confronto entre "passivo socioambiental" e "ativo 
socioambiental" seria zero. Ou seja, não há saldo favorável nem desfavorável do desempenho individual desta pessoa no contexto de sua vida privada. Caso esta pessoa adotasse outras providências compensatórias como, além de plantar uma árvore por mês, por exemplo, instalasse um equipamento de gás veicular e adotasse transporte solidário, ela, certamente, teria um saldo socioambiental positivo a seu favor.

$O$ ativo (custos socioambientais), teoricamente, seria maior que o passivo (efeitos socioambientais) provocado pela emissão de gás carbônico, agora reduzido pelo consumo alternativo de gás veicular ao invés da gasolina. Fazendo uma analogia com o cenário empresarial, seria como se contentar com o levantamento de emissão e das projeções de neutralização de carbono, via plantação de mudas de árvores.

Para calcular o impacto total do mundo dos negócios, devem ser somados os efeitos socioambientais de todo universo empresarial. Quanto maior for o mundo empresarial, menor será a quantidade de ativo socioambiental disponível por empresa. Como o consumo de insumos produtivos por parte das empresas estaria ocorrendo numa velocidade maior que a capacidade de reposição, significa que a continuidade das organizações está sob risco econômico de sobrevivência a longo prazo.

Este diagnóstico socioambiental, coerentemente com os fatores de análise da sustentabilidade pesquisados (Quadro 1), pode ser representado na forma de um balanço de sustentabilidade.

\subsection{Arquitetura da base de dados}

A base de dados de sustentabilidade empresarial está centrada na formulação de um indicador de desenvolvimento socioambiental - IDS que, de acordo com a proposta deste trabalho, refletiria o estágio em que se encontra a empresa em termos de sustentabilidade. A proposta de modelagem sistêmica desta arquitetura pode ser sintetizada na Figura 3, conforme evidenciada a seguir. 


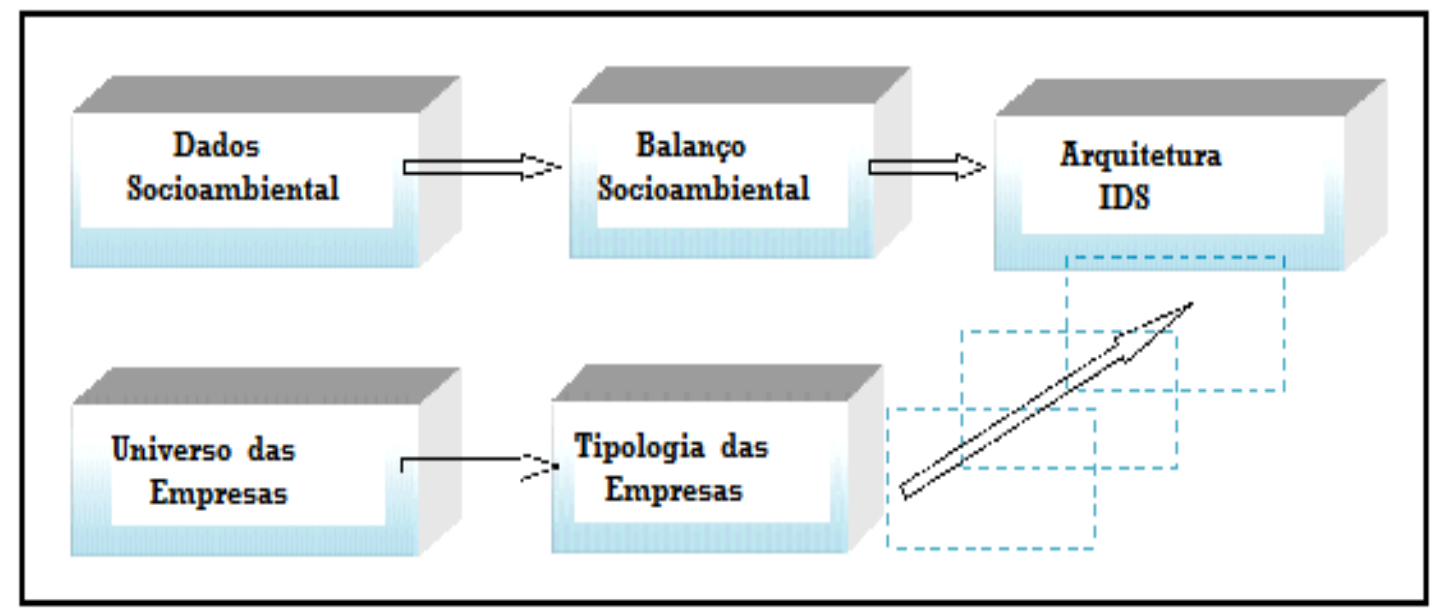

Figura 3: Modelo conceitual de diagnóstico socioambiental

A modelagem lógica da base de dados (Figura 4), conceitualmente, foi estruturada em quatro níveis de análise para se chegar aos valores dos indicadores de desenvolvimento socioambiental - IDS e correspondente balanço de sustentabilidade.

No primeiro nível é feito o diagnóstico socioambiental (critérios de diferenciação conforme enunciados na Figura 2) onde são analisadas as dimensões de sustentabilidade, transparência, governança corporativa, e capital humano.

Em um segundo nível, é estruturada a base de dados de IDS (Figura 5) das empresas do universo empresarial brasileiro, classificadas por setor econômico, de forma apriorística (com padrões de IDS variando em intervalos pré-estabelecidos), a partir dos fatores analisados do passivo ambiental. A métrica, singular a cada empresa analisada, apurada a posteriori, a partir do cumprimento dos quesitos estabelecidos como ativo ambiental, pode variar nos intervalos do IDS de cada setor econômico. Empresas do tipo A, por exemplo, tiveram os valores de IDS variando de 0 a 1 ; as do tipo 2 com valores no intervalo entre 1,1 a 2,0 e assim sucessivamente até as empresas do tipo J, com valores variando de 9,1 a 10. 


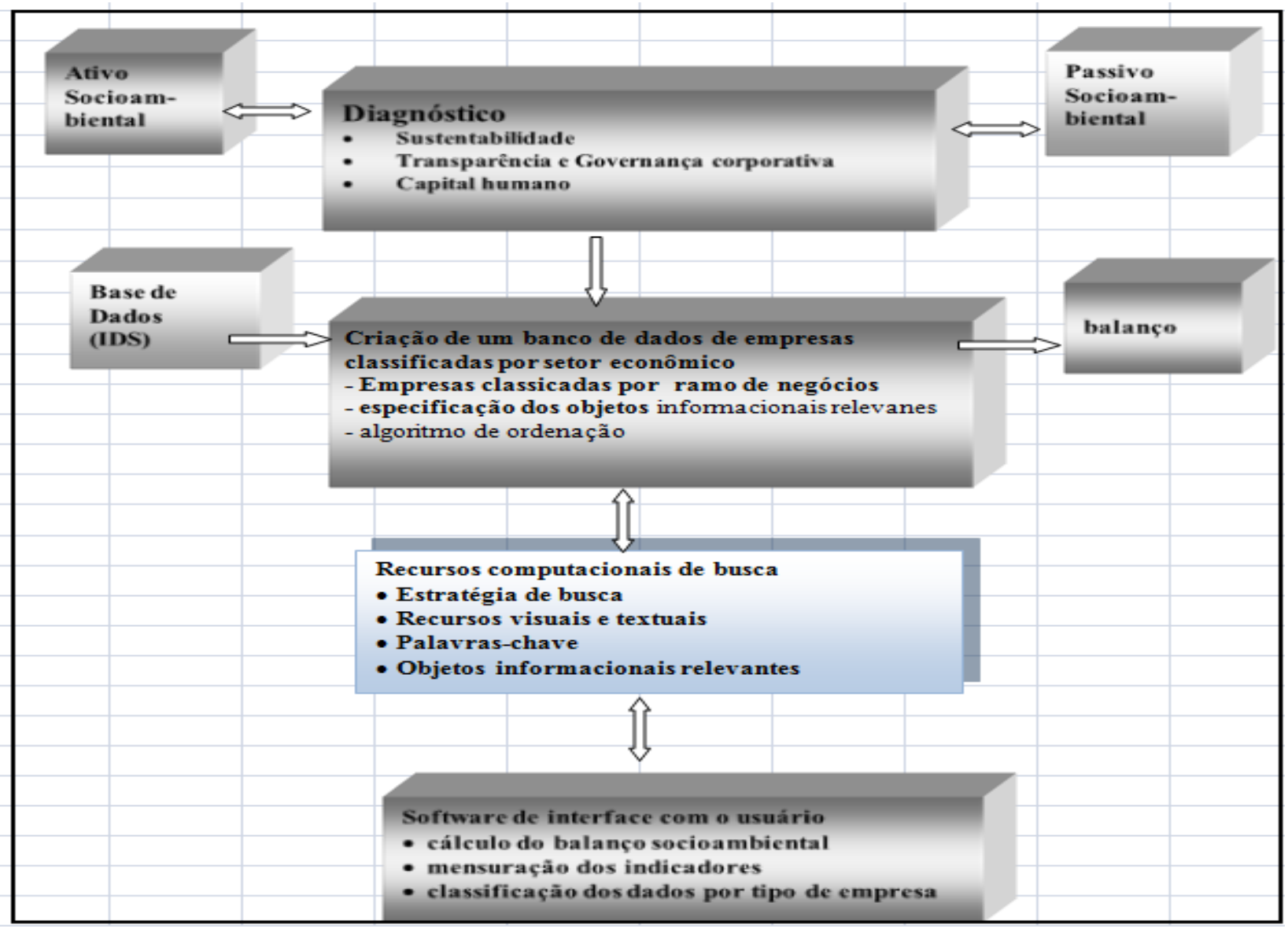

Figura 4: Modelagem da base de dados socioambientais

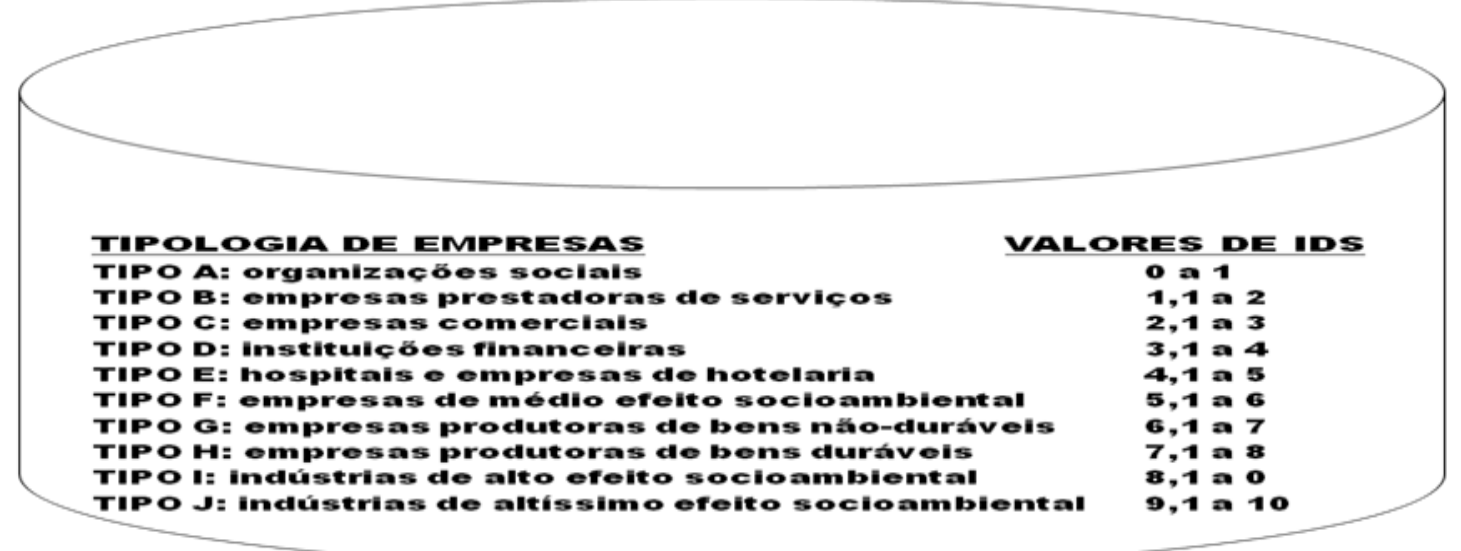

Figura 5: Base de Dados com métricas de IDS 
Como alternativa de custeio, poder-se-ia, simplesmente, efetuar o somatório em termos absolutos dos elementos que compõem o ativo socioambiental, apurando os custos de sustentabilidade. Porém nesta proposta optou-se pela sinalização desses custos como referencial de atuação da gestão da controladoria da empresa, na forma de IDS. Ou seja, o IDS na forma proposta neste modelo é um indicador derivado do desempenho socioambiental esperado na média das empresas que compõem cada um dos segmentos econômicos analisados. Isto permitiria o estabelecimento de uma escala para posicionar as empresas em face de seus diferentes estágios de sustentabilidade. No terceiro nível, são concebidos os recursos computacionais para geração do balanço socioambiental e, principalmente, de parâmetros de recuperação das informações de sustentabilidade.

E, no quarto nível, é criado o software de interface com o usuário, para permitir buscas, consultas e acesso on-line aos dados armazenados pelo sistema (balanço socioambiental, indicadores e demais informações de sustentabilidade). Em termos de programação e desenvolvimento de software, a modelagem da base de dados poderia ser explicitada conforme ilustração da Figura 6. Esses recursos podem ser sistematizados em um Sistema Informatizado de Monitoramento Ambiental e de Sustentabilidade Empresarial - SIMASE (TACHIZAWA; ANDRADE, 2008). A emissão desse balanço ocorre nesse quarto nível, observando enfoques diferenciados de sustentabilidade para diferentes organizações que, em razão de seu ramo de negócios, sofrem efeitos socioambientais distintos (Quadro 3). 


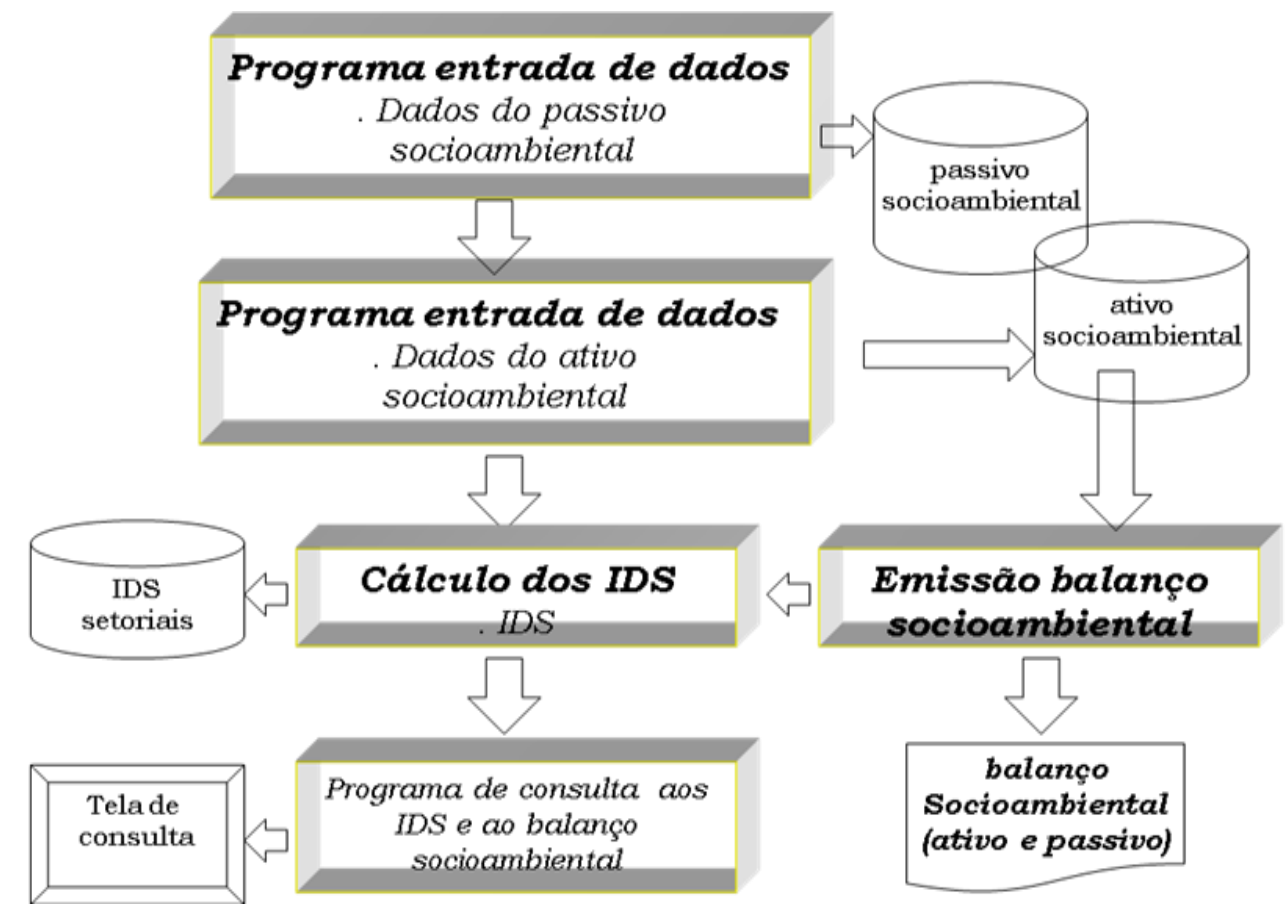

Figura 06: Representação da estrutura de programas do software SIMASE

O balanço socioambiental, composto do ativo e passivo, pode ser estruturado na forma de planilha considerando um diagrama de dupla entrada (modelo em "T"). Evidencia de um lado os efeitos socioambientais gerados pela organização (fatores de análise do Quadro 1 são quantificados, a priori, como passivo), e de outro, as decisões de sustentabilidade da sua Administração, com os correspondentes ônus econômicos (custos socioambientais apurados, a posteriori, como ativo) para fazer frente às exigências socioambientais decorrentes das características de sua cadeia produtiva. Dessa maneira, poder-se-ia apurar os custos socioambientais de uma determinada organização, bem como o comportamento de organizações pertencentes a um mesmo setor econômico.

Nesse quarto nível seria gerada analiticamente, ainda, uma tela de consulta por empresa, conforme exemplificado graficamente na Figura 8, para uma empresa hipotética "Alpha S/A". Nela são evidenciadas informações que caracterizam a empresa (nome da empresa, setor econômico e IDS) e aquelas inerentes ao cumprimento dos quesitos relacionados aos custos socioambientais (Ativo). 


\begin{tabular}{|c|c|}
\hline ATIVO (custos socioambientais) & PASSIVO (efeitos socioambientais) \\
\hline Sustentabilidade & Sustentabilidade \\
\hline 1. ABNT/ISO 14000 & \multirow[t]{3}{*}{$\begin{array}{l}\text { Exigências de sua cadeia produtiva (fornecedores, } \\
\text { clientes,...) }\end{array}$} \\
\hline 2. ABNT/ISO 16000 & \\
\hline 3. SA8000 (ou AA1000) & \\
\hline Transparência & Transparência \\
\hline $\begin{array}{l}\text { 4. Balanço social (Ethos, Akatu, GRI...) ou } \\
\text { relatório de sustentabilidade implementado }\end{array}$ & \multirow[t]{2}{*}{$\begin{array}{c}\text { Evidenciação externa dos resultados de sua } \\
\text { gestão junto aos públicos de interresse } \\
\text { (acionistas, investidores, instituições financeiras e } \\
\text { comunidade) }\end{array}$} \\
\hline 5. Código de ética implementado & \\
\hline Governança corporativa & Governança corporativa \\
\hline 6. Nível 1, 2, 3 ou 4 & \multirow[t]{2}{*}{$\begin{array}{l}\text { Boas práticas de governança junto aos seus } \\
\text { públicos (acionistas, investidores, instituições } \\
\text { financeiras e comunidade) }\end{array}$} \\
\hline 7. Novo mercado (ou ISE/DJSI) & \\
\hline Capital humano & Capital humano \\
\hline 8. Programa de clima organizacional & \multirow[t]{3}{*}{$\begin{array}{l}\text { Exigências de seus processos de gestão com } \\
\text { pessoas e de seu ambiente de trabalho. } \\
\text { Qualidade de vida e no trabalho. }\end{array}$} \\
\hline 9. Plano de carreira implementado & \\
\hline 10. Plano de remuneração estratégica & \\
\hline
\end{tabular}

Quadro 3: Estrutura do Balanço Socioambiental

Estes mesmos quesitos de custos de sustentabilidade, de forma alternativa, poderiam ser apurados em termos absolutos, como elementos de custeio do ativo socioambiental. A depender do setor econômico a que pertence a empresa, pode-se alterar os quesitos de custos, uma vez que eles variam em função das características da cadeia produtiva.

Uma empresa de serviços especializados, por exemplo, não precisaria de sistema de normatização do tipo ABNT/ISO14000, ou mesmo de boas práticas de governança corporativa, podendo dar lugar a outros quesitos pertinentes a esse tipo de empresa de prestação de serviços (por exemplo: implementação de projetos de cidadania corporativa, programas de capacitação de fornecedores, entre outros), ou seja, sistemicamente, as informações de criação do balanço socioambiental observariam a estrutura de dados ilustrada na Figura 6 explicitada a seguir e que é, meramente, uma visão sistêmica interna, baseada na dimensão do balanço explicitada no Quadro 3. 
Nesta visão do balanço socioambiental evidenciada na Figura 8, é exemplificada a situação de uma empresa do tipo J (Quadro 1), que é uma organização de altíssimo efeito socioambiental. O Passivo deve ser o espelho da tipologia estabelecida no Quadro 1, enquanto o Ativo representa o quanto de ações de sustentabilidade a empresa adota.

Neste caso existe uma defasagem entre o que seria exigido, normalmente, para uma empresa de altíssimo efeito socioambiental e o que é adotado de práticas compensatórias desses impactos provenientes das peculiaridades dessa empresa. $\mathrm{Ou}$ seja, a empresa sob análise, para ter efeito nulo (Ativo igual ao Passivo), teria que compensar cada ônus causado pela empresa, que é o Passivo, por equivalente prática do lado do Ativo.

Os elementos que compõem o Passivo e correspondente contrapartida do lado do Ativo podem ser desdobrados em subitens de análise, a depender do tipo de empresa (como foi o caso do tópico balanço social e cargos e salários, que no exemplo da empresa do tipo $\mathrm{J}$, se desmembraram em 2 subitens). Por exemplo, no caso de uma instituição financeira (bancos e afins), não deve haver ênfase em termos de proteção ambiental e, portanto, não haveria exigência em termos de ISO14000. No entanto, elemento como a ética empresarial mereceria destaque neste tipo de organização podendo, seu código de ética ser desmembrado em itens como: ética em relação aos clientes; ética em relação aos fornecedores; ética em relação ao seu público interno; código de ética disponibilizado na Internet e Intranet.

Fazendo uma análise das informações de sustentabilidade (tela de consultas da Figura 8), e comparando-a com outras organizações concorrentes do mesmo setor econômico (benchmarking), podem ser estabelecidas ênfases de estratégias ambientais e sociais específicas para a empresa focalizada. Isto permitiria criar condições para o aprimoramento das práticas empresariais corporativas na medida em que as estratégias de negócios passariam a se apoiar cada vez mais em metas de sustentabilidade.

Dada a convergência com os objetivos corporativos, as informações de sustentabilidade de uma base de dados, possibilitam que as empresas definam qual a 
melhor estratégia para a geração de valor, explorando o potencial de crescimento econômico, de forma integrada com suas ações socioambientais.

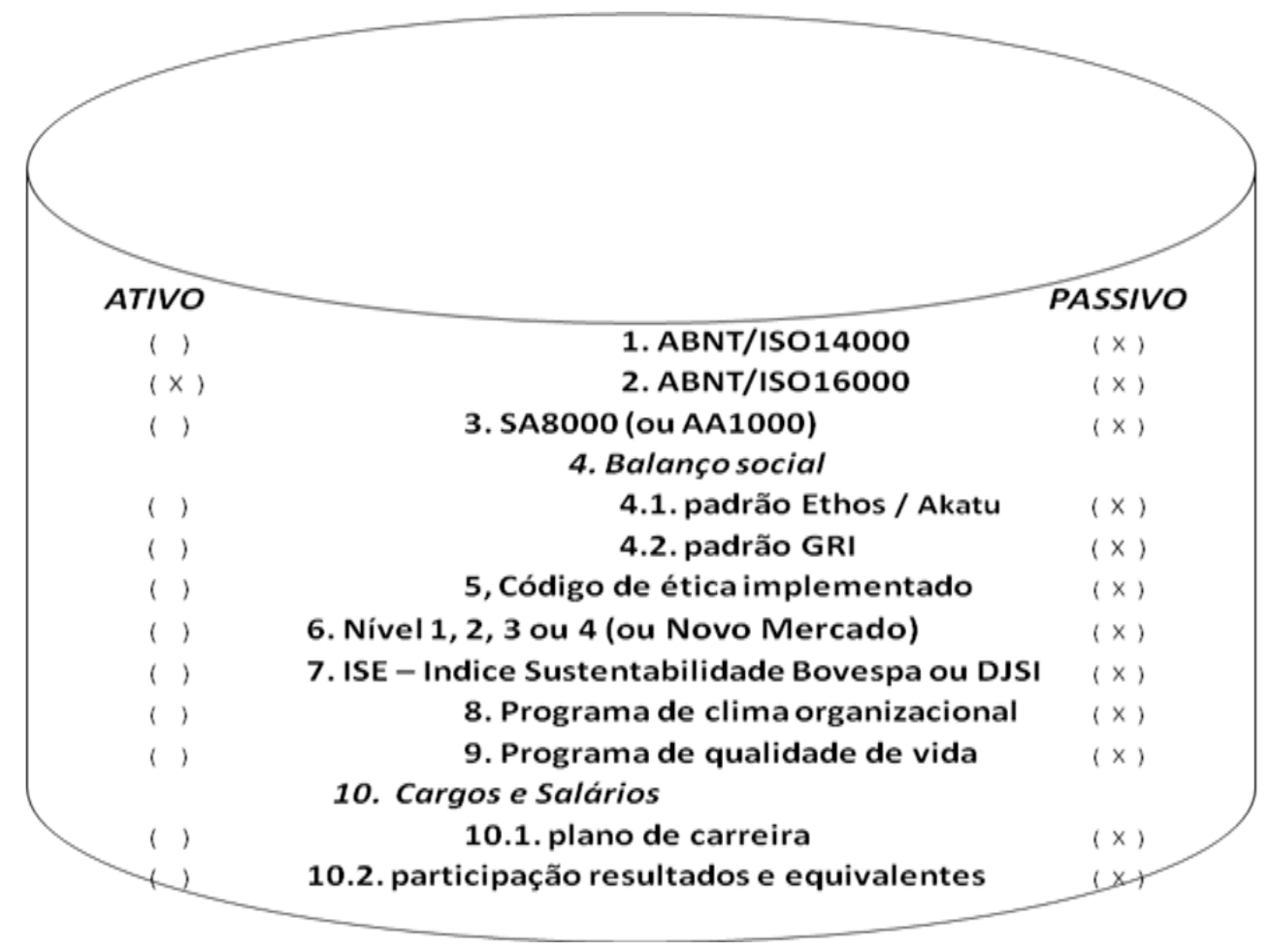

Figura 7: Visão sistêmica do programa de criação do balanço socioambiental 


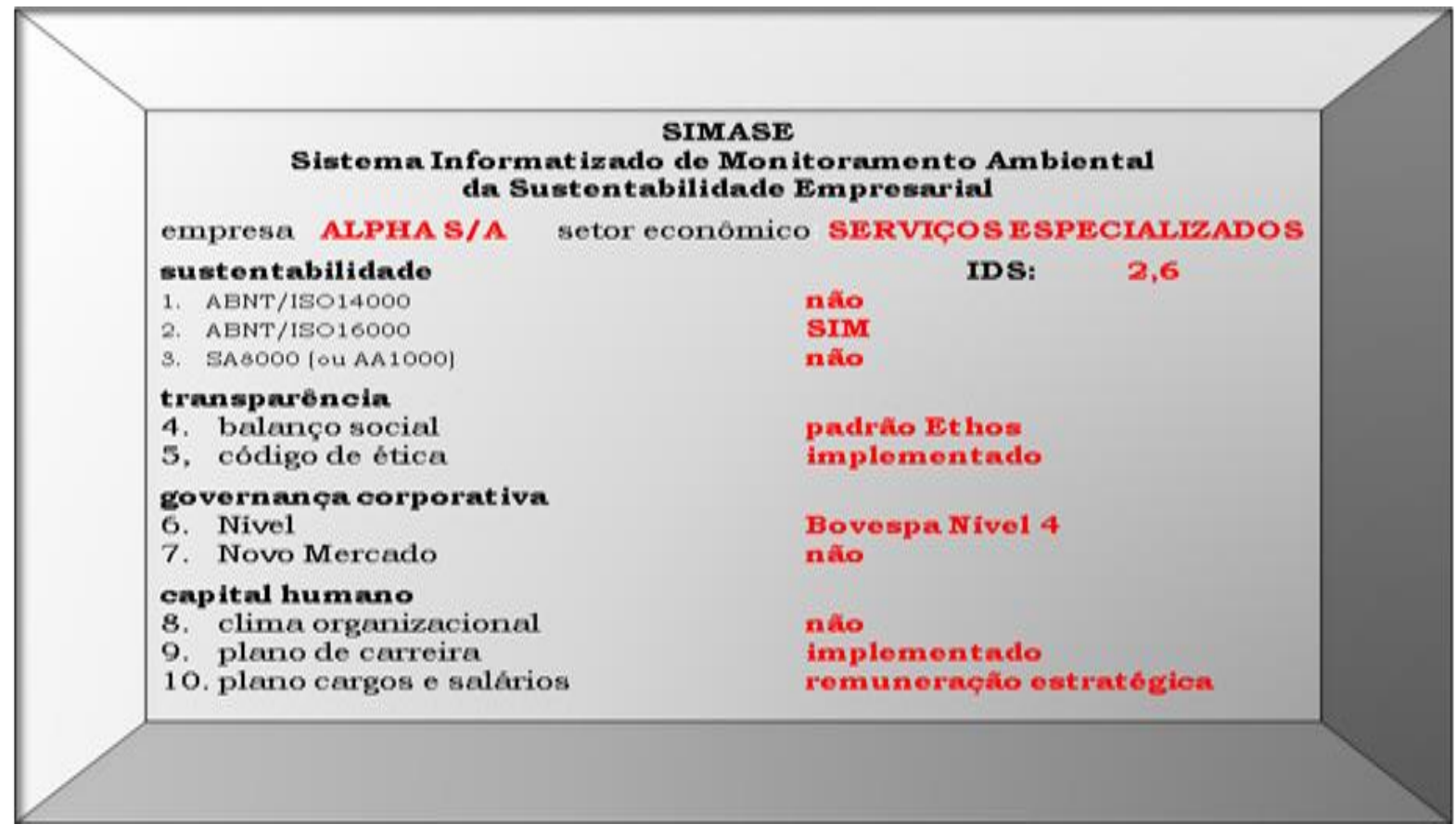

Figura 08: Representação da Tela de Consultas Customizada por Empresa

\section{CONCLUSÃO}

O objetivo deste artigo foi conceber uma arquitetura de base de dados para subsidiar o monitoramento e direcionamento da gestão de custos e de controladoria nas empresas. Ela sinalizaria os requisitos necessários para o processo de tomada de decisões de sustentabilidade, de forma convergente com os objetivos estratégicos da organização.

Tal modelo sugere que sejam adotados enfoques distintos de gestão de custos inerentes à sustentabilidade para diferentes tipos de organizações que, em razão de seu ramo de negócios, sofrem efeitos socioambientais diferenciados.

Além de refletir o estágio de sustentabilidade em que se encontra a empresa analisada, a arquitetura permitiria o mapeamento socioambiental dos diferentes segmentos econômicos do universo empresarial brasileiro. No contexto específico de uma determinada organização, possibilitaria que fossem planejadas decisões empresariais, indutoras de custos socioambientais, em sua cadeia produtiva e de ações voltadas à evidenciação (disclosure) contábil. 
O modelo proposto partiu do pressuposto de que os resultados corporativos passam a depender cada vez mais de decisões de controladoria que levem em conta que: a) não há conflito entre lucratividade e a questão socioambiental; b) clientes e comunidade passam a valorizar cada vez mais a proteção do meio ambiente; c) a demanda e, portanto, o faturamento das empresas sofre crescentes pressões e depende diretamente do comportamento de consumidores que enfatizarão suas preferências para produtos e organizações eticamente corretas.

Neste contexto, ganha importância uma arquitetura de informações de custos socioambientais, dentro dos contornos delineados neste trabalho, a ser implementada com o suporte dos recursos das tecnologias da informação.

Outros resultados específicos, decorrentes da implementação dessa arquitetura poderiam ser obtidos quanto à evidenciação externa, com oportunidade e clareza, possibilitando a perfeita compreensão, por parte dos stakeholders, da verdadeira situação que se encontra a organização.

Dessa forma, dados decorrentes do balanço de sustentabilidade e mesmo do IDS apurado, poderiam fazer parte do Relatório da Administração que acompanha as Demonstrações Contábeis, e do próprio balanço social, normalmente divulgado pela empresa.

\section{REFERÊNCIAS}

BESSERMAN, Sérgio. (2003). A Lacuna das informações ambientais. In: TRIGUEIRO, André (Coord.). Meio Ambiente no século 21. Rio de Janeiro: Sextante.

BOLSA DE VALORES DE SÃO PAULO. BOVESPA. (2008). São Paulo. Disponível no site www.bovespa.com.br. Acesso em: 30/abr/2008.

BRONN P. S.; VRIONI, A. B. (2001). Corporate social responsibility and cause-related marketing: an overview. International Journal of Advertising, n.20, n.2.

BUYTENDIJK, F.; WOOD, B.; GEISHECKER, L. (2004). Mapping Road to Corporate Performance Management. Gartner Group, January.

DRAPER, S. W.; DUNLOP, M.D. (2002). New IR-New Evaluation: the impact of interaction and multimedia on information retrieval and its evaluation. Disponível em: 
Monitoramento de Custos e do Passivo Socioambiental: Uma Proposta de Arquitetura de Dados de Sustentabilidade

Takeshy Tachizawa

http://www.cs.strath.ac.uk/ mdd/research/publications/nrhm/new_IR_new_eval.pdf. Acesso em: 30/abr/2008.

EVANS, P.; WÜRSTER, T. (2000). Blown to Bits: How the Economics of Information Transforms Strategy, Boston. Harvard Business School Press.

GLASER, B.; STRAUSS, A. (1967). The Discovery of Grounded Theory, Chicago: Aldine.

GLASER, B. (1998). Doing grounded theory: issues and discussions. Mill Valley, Ca: Sociology Press.

GLASER, B.; HOLTON, J. (2004). Remodeling Grounded Theory. The Grounded Theory Review. V.4, n.1, November.

HENDERSON, H. (2001). Transcendendo a economia. Tradução de Merle Scoss. (10 ed.). São Paulo: Editora Cultrix.

INSTITUTO BRASILEIRO DE GEOGRAFIA E ESTATÍSTICA - IBGE. (2008). Indicadores de desenvolvimento sustentável - Brasil. Brasília: IBGE.

INSTITUTO BRASILEIRO DE ANÁLISES SOCIAIS E ECONÔMICAS. Guia de Balanço Social - IBASE. Disponível em: www.ibase.org.br. Acesso em: 01/mai/2008.

INSTITUTO ETHOS DE RESPONSABILIDADE SOCIAL. Matriz de Evidências de Sustentabilidade, Banco de Práticas e Ferramentas de gestão: Indicadores Ethos, Guia de Elaboração de Balanço Social. Disponível em: www.ethos.org.br. Acesso em: 01/mai/2008.

LAUDON, K.C.; LAUDON, J.P. (2000). Management information systems: organization and technology in the networked enterprise. New Jersey: Prentice-Hall.

ONU - Organização das nações Unidas. Contabilidad financiera y presentación de informes ambientales por las empresas. http://www.unetad.org/sp/sphome.htm. Acesso em 15/nov/2007.

ORGANIZATION FOR ECONOMIC CO-OPERATION AND DEVELOPMENT - OECD Core set of Indicators for Environmental Performance Reviews. A synthesis report by the Group on the State of the Environment. Environment Monographs $N^{\circ}$ 83. Paris: OECD, $1993 . \quad$ Disponível em: http://lead.virtualcentre.org/en/dec/toolbox/Refer/gd93179.pdf. Acesso em 30/abr/2008.

PROGRAMA DAS NAÇÕES UNIDAS PARA O DESENVOLVIMENTO. (2007). Relatório de Desenvolvimento Humano 2007/2008: Combater as alterações climáticas: Solidariedade humana num mundo dividido. PNUD, UN Plaza, New York. Disponível 
em: http://www.pnud.org.br/arquivos/rdh/rdh20072008/hdr_20072008_pt_complete.pdf. Acesso em: 01/fev/2008.

RAYNARD, P.; FORSTARTER, M. (2002). Corporate Social Responsibility: Implications for Small and Medium Enterprises in Developing Countries. United Nations Industrial Development Organization, Viena. Disponível em: http://www.unido.org/doc/5162. Acesso em 01/fev/2008.

REVISTA EXAME. (2008). Melhores e Maiores e As Melhores Empresas em Cidadania Corporativa, São Paulo. Editora Abril.

RIBEIRO, M. S. (1998). Custeio das atividades de natureza ambiental. (Tese de Doutorado). Faculdade de Economia, Administração e Contabilidade, Universidade de São Paulo. São Paulo.

STRAUSS, A.; CORBIN, J. (1994). Grounded Theory Methodology - An Overview. Handbook of Qualitative Research, N.K. Denzin and Y.S. Lincoln (eds.), Sage Publications, Thousand Oaks, CA.

STRAUSS, A.; CORBIN, J. (1997). Grounded Theory in Practice, Sage Publications, London.

TACHIZAWA, T. (2009). Gestão Ambiental e Responsabilidade Social Corporativa. 6a. edição revista e ampliada. São Paulo: Editora Atlas.

TACHIZAWA, T. e ANDRADE, R.O.B. (2008). Gestão Socioambiental: estratégias na nova era da sustentabilidade. São Paulo: Editora Campus.

TINOCO, J. E. P. (2001). Balanço social: uma abordagem da transparência e da responsabilidade pública das organizações. São Paulo: Atlas.

Data de Submissão: 10/04/2009

Data de Aceite: 26/03/2010 